Epstein, S. I., Doty, P. \& Boyd, W. C. A. (1956). J. Amer. chem. Soc. 78, 3306.

Epstein, S. I. \& Singer, S. J. (1958). J. Amer, chem. Soc. 80, 1274.

Grabar, P. \& Williams, C. A. (1955). Biochim. biophys. Acta, 17, 67.

Gyenes, L. \& Sehon, A. H. (1960). Canad. J. Biochem. Physiol. 38, 1235.

Gyenes, L. \& Sehon, A. H. (1962). J. Immunol. 89, 483.
Lapresle, C. \& Webb, T. (1960a). Ann. Inst. Pasteur, 99, 523.

Lapresle, C. \& Webb, T. (1960b). Biochem. J. 76, 538.

Lapresle, C. \& Webb, T. (1962). Biochem. J. 84, 455.

Schachman, H. K. (1959). Ultracentrifugation in Biochemistry, p. 75. New York: Academic Press Inc.

Singer, S. J. \& Campbell, D. H. (1952). J. Amer. chem. Soc. 74, 1794.

Webb, T. \& Lapresle, C. (1961). J. exp. Med. 114, 43.

Biochem. J. (1964) 91, 31

\title{
The Biosynthesis of Streptomycin
}

\section{INCORPORATION OF ${ }^{14}$ C-LABELLED COMPOUNDS INTO STREPTOSE AND $N$-METHYL-L-GLUCOSAMINE}

\author{
BY D. J. CANDY, N. L. BLUMSOM AND J. BADDILEY \\ Department of Organic Chemistry, University of Newcastle upon Tyne
}

\section{(Received 11 September 1963)}

Although the structure of streptomycin has been known for some time, the process of its biosynthesis by Streptomyces griseus has not yet been elucidated. Blumsom \& Baddiley (1961) examined extracts of $S$. griseus for nucleotide-sugar compounds which may be involved in synthesis of the streptose and $N$-methyl-L-glucosamine moieties of streptomycin. They found thymidine diphosphate rhamnose a possible intermediate for streptose, but no compounds more closely related to streptomycin were identified. Other workers have grown S. griseus in the presence of labelled compounds and examined the incorporation of the isotope into the streptomycin produced. Such experiments were first carried out by Karow, Peck, Rosenblum \& Woodbury (1952), who showed that $\left[{ }^{14} \mathrm{C}_{6}\right]$ glucose was incorporated into the streptomycin molecule. Hunter \& Hockenhull (1955) carried out a similar experiment and degraded the streptomycin. They found that the streptidine, streptose and $N$-methyl-Lglucosamine residues had similar specific activities, showing that they were all equally derived from glucose. Hunter, Herbert \& Hockenhull (1954) grew S. griseus in the presence of ${ }^{14} \mathrm{CO}_{2}$ and found that streptomycin subsequently isolated was labelled almost exclusively in the guanidine residues. The specific activity of the resulting streptomycin was considerably decreased by the presence of arginine in the growth medium, which suggests that arginine can act as a source of the guanidine in the antibiotic. Hunter \& Hockenhull (1955) also added ${ }^{14} \mathrm{C}$-labelled $N$-methyl-L-glucosamine to the growth medium and found that the $N$-methyl-Lglucosamine residue in the streptomycin contained a considerable amount of isotope. Silverman \& Rieder (1960) studied the formation of this amino sugar residue and obtained results that indicate that it is formed from glucose without breakage of the hexose carbon chain.

The source of the $N$-methyl group of $N$-methylL-glucosamine has not hitherto been studied directly, although it is known that $\mathrm{L}$-methionine can stimulate the production of streptomycin (Galanina \& Agatov, 1959; Majumdar \& Kutzner, 1962). The $S$-methyl group of methionine seemed a likely source of the methyl group, and for this reason we have studied the incorporation of radio-

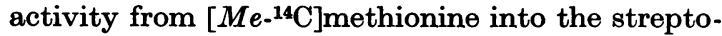
mycin molecule. We have also studied the formation of the streptose moiety of streptomycin from labelled compounds. $\left[{ }^{14} \mathrm{C}\right]$ Formate was used as a possible precursor of the $C$-formyl group of streptose, and specifically labelled glucose was used to discover the source of the main carbon chain.

\section{MATERIALS AND METHODS}

Production of streptomycin. Streptomyces griseus (Glaxo strain L 118) was grown on slopes composed of: bactoagar (Difco Laboratories), $2 \%$; yeast extract (Difco), $1 \%$; soya peptone (Oxoid), $2 \%$; glycerol, $3 \%$. The spores produced were used to inoculate $20 \mathrm{ml}$. of a medium composed of: nutrient broth no. 2 (Oxoid), $2.5 \%$; glucose, $1 \%$. The culture was grown for $24 \mathrm{hr}$. at $28^{\circ}$ on a shaker (140 oscillations/min.). A $5 \mathrm{ml}$. inoculum was then transferred to a $500 \mathrm{ml}$. conical flask containing $50 \mathrm{ml}$. of Carvajal's (1957) medium, $0.5 \mathrm{~g}$. of soya-bean meal and the radioactive compound $(0.3 \mathrm{mc}$ for the formate experiment; $0.08 \mathrm{mc}$ for the other experiments). The culture was grown for a 
further 4 days under the above conditions, and streptomycin was isolated by the method of Hunter \& Hockenhull (1955). The radioactive product was then diluted with unlabelled streptomycin (usually $1 \mathrm{~g}$.) and purified by twice recrystallizing as its reineckate. Streptomycin reineckate was converted into the hydrochloride by acidification with $\mathrm{HCl}$ and extraction with pentan-1-ol. Degradation according to Scheme 1 was carried out by the methods described below.

Degradation of streptomycin. (a) Streptidine. Streptomycin hydrochloride $(0.5 \mathrm{~g}$.) was dissolved in $\mathrm{N}$-sulphuric acid $\left(2.5 \mathrm{ml}\right.$.) and the solution was kept at $37^{\circ}$ for $48 \mathrm{hr}$. An equal volume of methanol was added and the mixture was kept for a further $24 \mathrm{hr}$. at $37^{\circ}$. An equal volume of acetone was added and after $2 \mathrm{hr}$. at $0^{\circ}$ the insoluble streptidine sulphate was filtered off (yield, $122 \mathrm{mg}$.). The filtrate, containing methyl streptobiosaminide dimethylacetal hydrochloride, was used for the preparation of $N$-methyl-Lglucosamine (see below). The streptidine sulphate was recrystallized from hot water and converted into its octaacetate (Peck et al. 1946) which was recrystallized from chloroform-light petroleum (b.p. $40-60^{\circ}$ ) and then from chloroform-ether to yield $39 \mathrm{mg}$. of white product, m.p. 250-252 .

(b) $N$-Methyl-L-glucosamine. The solution of methyl streptobiosaminide dimethylacetal hydrochloride was evaporated to remove organic solvents and then treated with an excess of Amberlite IR-45 ( $\mathrm{OH}^{-}$form) resin to remove sulphate. After removal of the resin and evaporation, the residue was refluxed for $2 \mathrm{hr}$. in conc. $\mathrm{HCl}$ (Kuehl, Flynn, Holly, Mozingo \& Folkers, 1947). The hydrolysate was washed with chloroform, evaporated to dryness and acetylated with acetic anhydride-pyridine $(1: 1, v / v)$ for 3 days at $5^{\circ}$. After pyridine and excess of acetic anhydride had been removed under reduced pressure, the residue was dissolved in water and extracted with chloroform. The
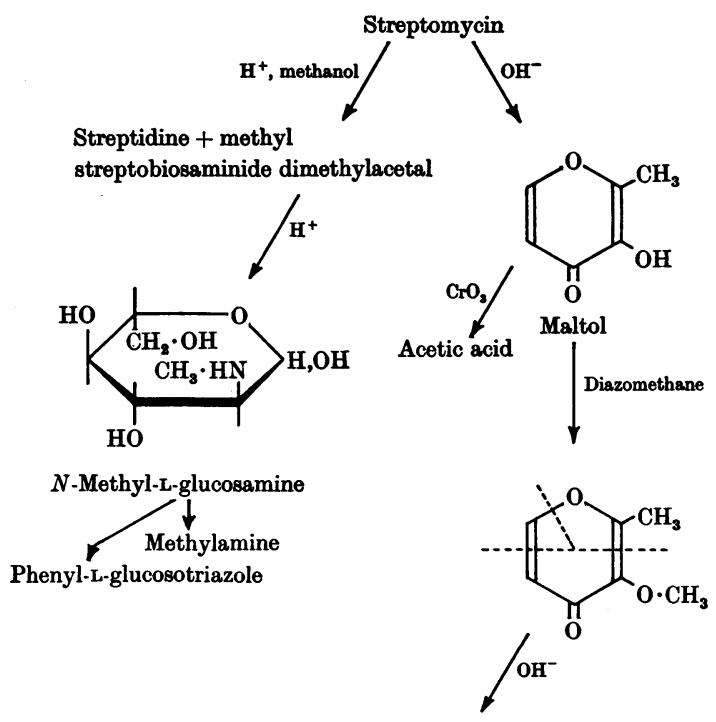

Formic acid + acetic acid + methoxyacetone

Scheme 1. Degradation of streptomycin. Experimental details are given in the text. chloroform was evaporated and the residue was recrystallized three times from ether to yield white crystals of the penta-acetate of $N$-methyl-L-glucosamine, m.p. $160^{\circ}$ (yield, $36 \mathrm{mg}$.).

$N$-Methyl-L-glucosamine hydrochloride was prepared from the penta-acetyl derivative by refluxing for $2 \mathrm{hr}$. in $2 \mathrm{~N}-\mathrm{HCl}$. The solution was evaporated under reduced pressure and the product was recrystallized twice from ethanol (yield, $0.99 \mathrm{~g}$., from $9 \mathrm{~g}$. of penta-acetyl derivative). Methylamine was prepared from $0.5 \mathrm{~g}$. of $N$-methyl-Lglucosamine hydrochloride by alkali degradation according to the method of Brink, Kuehl, Flynn \& Folkers (1946). The methylamine (derived from the $N$-methyl group of the amino sugar) was converted into its benzoyl derivative and recrystallized from a mixture of ether and light petroleum (b.p. $40-60^{\circ}$ ) to give $52 \mathrm{mg}$. of white solid, m.p. 80-81 .

Phenyl-L-glucosotriazole was prepared from $250 \mathrm{mg}$. of $N$-methyl-L-glucosamine by the method of Kuehl et al. (1947). The product (9 mg.) was a white crystalline solid, m.p. $196^{\circ} ;[\alpha]_{D}^{20}+73^{\circ}$ in pyridine.

(c) Streptose. Streptomycin hydrochloride (3.1 g.) was degraded by heating in dilute alkali to give maltol (Schenck \& Spielman, 1945), a product which is derived from the streptose moiety. The maltol was purified by extraction into chloroform and recrystallization from ethanol (twice) to yield $315 \mathrm{mg}$. of white crystalline solid, m.p. 160-161 ${ }^{\circ}$.

Maltol (74 mg.) was oxidized by the Kuhn-Roth procedure (cf. Milton \& Waters, 1955) to acetic acid (derived from C-4 and C-5 of streptose). This was further degraded to carbon dioxide (C-4 of streptose) and methylamine (C-5 of streptose) by the method of Phares (1951). The carbon dioxide was collected in aqueous piperidine and the methylamine was converted into its benzoyl derivative (yield, 8.2 mg.).

An alternative degradation of maltol was used to obtain C-1 and C-2 plus C-3 plus C-3': the maltol (310 mg.) was converted into $O$-methylmaltol (280 mg.) with diazomethane, and this was degraded with barium hydroxide to give formic acid (C-1 of streptose), methoxyacetone (C-2, C-3 and C-3') and acetic acid (C-4 and C-5) (Peratoner \& Tamburello, 1905). The methoxyacetone was separated from the other products by distillation from the alkaline solution (yield, $114 \mathrm{mg}$.). The formic acid and acetic acid were then obtained by steam-distillation from the acidified hydrolysate and were separated on a Celite column (Phares et al. 1952) (yields: acetic acid, 1.7 m-moles; formic acid, 1.3 m-moles).

Measurement of radioactivity. This was carried out with scintillation-counter assembly no. NE 8301 (Nuclear Enterprises Ltd.). Aqueous solutions were examined with scintillator NE 220, and non-aqueous solutions with scintillator NE 213. The efficiencies of the two scintillators were very similar (approx. 70\%) under the conditions employed, but values obtained with NE 213 were converted into the equivalent value for NE 220 by a conversion factor (obtained by comparing a standard solution of $\left[{ }^{14} \mathrm{C}\right]$ glycerol in butan-1-ol in the two scintillators). With all substances the radioactivity was linear with respect to concentration, showing the absence of significant selfabsorption effects. In each case this was confirmed by the addition of a glycerol standard to the compound: the increased counting rate was equal to that of the glycerol standard alone. The compounds examined were: streptidine as its octa-acetate in dioxan; $N$-methyl-L-glucosamine as 
its penta-acetate in butan-1-ol; methylamine as its benzoyl derivative in dioxan; phenyl-L-glucosotriazole in dioxan; maltol in dioxan; methoxyacetone in water; acetic acid in water; formic acid in water; streptomycin hydrochloride in water; carbon dioxide in water containing piperidine.

Other analytical methods. Streptomycin was determined by the ferric-maltol reaction (St John, Flick \& Tepe, 1951), methoxyacetone by the iodoform reaction (Morgan, Bardwell \& Cullis, 1950), acetic acid by the method of Hutchens \& Kass (1949) and formic acid by the colorimetric method of Wood \& Gest (1957). Melting points were not corrected.

Chemicals. Radioactive chemicals were obtained from The Radiochemical Centre, Amersham, Bucks., and had the following specific activities: $\left[1{ }^{14} \mathrm{C}\right]$ glucose, $3.68 \mathrm{mc} / \mathrm{m}$ mole; $\left[6-{ }^{14} \mathrm{C}\right]$ glucose, $2.36 \mathrm{mc} / \mathrm{m}$-mole; $\left[M e-{ }^{14} \mathrm{C}\right]$ methionine, $18.3 \mathrm{mc} / \mathrm{m}$-mole; sodium $\left[{ }^{14} \mathrm{C}\right]$ formate, $5 \mathrm{mc} / \mathrm{m}$-mole.

\section{RESULTS}

$\left[\mathrm{Me}-{ }^{14} \mathrm{C}\right]$ Methionine. The streptomycin produced by $S$. griseus grown in the presence of $\left[M e-{ }^{14} \mathrm{C}\right]$ methionine contained approx. $7 \%$ of the added ${ }^{14} \mathrm{C}$. Table 1 shows the distribution of ${ }^{14} \mathrm{C}$ in the three main components of the streptomycin molecule. The $N$-methyl-L-glucosamine was diluted with carrier before further degradation (results in Table 2). The results show that the $S$-methyl group of L-methionine is incorporated into the streptomycin molecule and that the ${ }^{14} \mathrm{C}$ is located almost entirely in the $N$-methyl group of $N$-methyl-Lglucosamine.

$\left[{ }^{14} \mathrm{C}\right]$ Formate. Streptomycin produced by $S$. griseus grown in the presence of $\left[{ }^{14} \mathrm{C}\right]$ formate acquired only $0.016 \%$ of the total radioactivity present in the culture. In contrast, the streptomycin formed accounted for $0.54 \%$ of the total substrate carbon in the medium. Thus formate is only incorporated into streptomycin at a very low rate.

The specific activity of the streptomycin was 38 counts/min./ $\mu$ mole, whereas the specific activity of maltol prepared from it was negligible (less than $0.5 \mathrm{count} / \mathrm{min} . / \mu \mathrm{mole})$. It is therefore clear that formate does not act as a precursor of streptose under the conditions used.

$\left[1-{ }^{14} \mathrm{C}\right]$ Glucose and $\left[6-{ }^{14} \mathrm{C}\right]$ glucose. Table 3 shows the distribution of radioactivity in the streptose moiety of streptomycin produced by cultures grown in the $e^{\circ}$ presence of $\left[1^{14} \mathrm{C}\right]$ glucose and $\left[6-{ }^{14} \mathrm{C}\right]$ glucose.

\section{DISCUSSION}

The results obtained with $\left[M e^{-14} \mathrm{C}\right]$ methionine show that the $S$-methyl group of L-methionine can serve as a source of the $N$-methyl group of $N$. methyl-L-glucosamine. This provides an explanation of observations (Galanina \& Agatov, 1959; Majumdar \& Kutzner, 1962) that under certain
Table 1. Distribution of radioactivity in streptomycin produced by Streptomyces griseus grown in the presence of $\left[\mathrm{Me}-{ }^{14} \mathrm{C}\right]$ methionine

Experimental details are given in the text.

$\begin{array}{cc}\begin{array}{c}\text { Total } \\ \text { radioactivity } \\ \text { (counts/min.) }\end{array} & \begin{array}{c}\text { Sp. activity } \\ \text { (counts/ } \\ \text { min./ } / \mu \text { mole) }\end{array} \\ 1384 \pm 7 & 3890 \\ 3 \pm 0 \cdot 1 & 3 \\ 1235 \pm 5 & 3870 \\ 65 \pm 0 \cdot 4 & 15\end{array}$

Table 2. Distribution of radioactivity in N-methylL-glucosamine from streptomycin produced by Streptomyces griseus grown in the presence of $\left[\mathrm{Me}-{ }^{14} \mathrm{C}\right]$ methionine

Experimental details are given in the text.

$\begin{array}{cc}\text { Total } & \text { Sp. activity } \\ \text { radioactivity } & \begin{array}{c}\text { (counts/ } \\ \text { (counts/min.) }\end{array} \\ \text { min. } \mu \text { mole) }\end{array}$

conditions L-methionine can stimulate the production of streptomycin. A similar transfer of the $S$-methyl group of methionine to form an $N$ methyl group has been found for the sugar desosamine (part of the erythromycin molecule) by Majer, Puza, Dolezilova \& Vanek (1961). The $S$ methyl group of methionine is also the source of both $C$-methyl and $O$-methyl groups of branchedchain sugars of some antibiotics (Birch, Cameron, Holloway \& Rickards, 1960; Corcoran, 1961; Majer et al. 1961). Corcoran (1961) also found that $\left[{ }^{14} \mathrm{C}\right]$ formate was not incorporated into the methyl group of cladinose; our results suggest likewise that the $N$-methyl group of $N$-methyl-L-glucosamine is not derived from formate.

Neither $\left[M e-{ }^{14} \mathrm{C}\right]$ methionine nor $\left[{ }^{14} \mathrm{C}\right]$ formate was incorporated into streptose. This means that the $C$-formyl carbon atom of streptose does not arise from either of these sources, although the possibility of an alternative precursor of $\mathrm{C}_{1}$ units is not ruled out. However, the fact that much of the C-6 of glucose appears in C-5 of streptose, and much of the C-1 of glucose appears in C-1 of streptose, suggests that the hexose unit as a whole is incorporated into the streptose molecule. The condensation of a $\mathrm{C}_{2}$ unit and a $\mathrm{C}_{4}$ unit to form streptose, as suggested by Hough \& Jones (1951), is, therefore, not a likely mechanism. It seems more probable that the formation of streptose takes place by a rearrangement of the hexose carbon skeleton such that either C-3 or C-4 becomes the C-3' branch carbon atom of the 
Table 3. Distribution of radioactivity in maltol from streptomycin produced by Streptomyces griseus grown in the presence of $\left[1{ }^{14} \mathrm{C}\right]$ glucose and $\left[6-{ }^{14} \mathrm{C}\right]$ glucose

\begin{tabular}{|c|c|c|c|c|}
\hline & $\begin{array}{l}\text { Carbon atoms } \\
\text { derived from } \\
\text { streptose }\end{array}$ & $\begin{array}{c}\text { Total } \\
\text { radioactivity } \\
\text { (counts/min.) }\end{array}$ & $\begin{array}{c}\text { Sp. activity } \\
\text { (counts/min./ } \\
\mu \mathrm{mole})\end{array}$ & $\begin{array}{c}\text { Sp. activity } \\
\text { (\% of that } \\
\text { of maltol) }\end{array}$ \\
\hline \multicolumn{5}{|c|}{$\left[1{ }^{14} \mathrm{C}\right]$ Glucose experiment } \\
\hline Maltol & All & $1544 \pm 4$ & $64 \cdot 6$ & 100 \\
\hline Methoxyacetone & $2,3,3^{\prime}$ & $175 \pm 1$ & $9 \cdot 2$ & $14 \cdot 2$ \\
\hline Acetic acid & 4,5 & $269 \pm 2$ & 12.5 & $19 \cdot 4$ \\
\hline Formic acid & 1 & $537 \pm 2$ & 43. 7 & 67.5 \\
\hline \multicolumn{5}{|c|}{$\left[6-{ }^{14} \mathrm{C}\right]$ Glucose experiment } \\
\hline Maltol & All & $546 \pm 3$ & 113 & 100 \\
\hline Methylamine & 5 & $523 \pm 3$ & 86 & 76 \\
\hline \multirow[t]{2}{*}{ Carbon dioxide } & & $34 \pm 0 \cdot 4$ & 1.5 & 1.4 \\
\hline & $1,2,3,3^{\prime}$ & (by d & ənce) & $22 \cdot 6$ \\
\hline
\end{tabular}

(A)

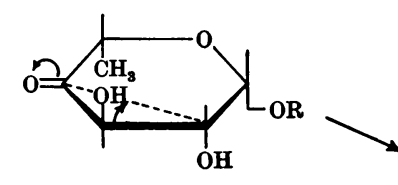

(B)

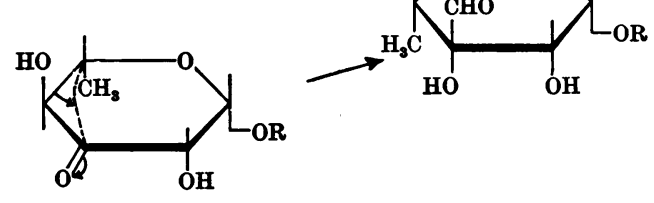

$\mathbf{R}=$ Thymidine $\mathbf{5}^{\prime}$-pyrophosphate

Scheme 2. Possible formation of streptose from intermediates in rhamnose biosynthesis.

product. Such a mechanism has been suggested by Blumsom \& Baddiley (1961); it involves structure (A) or (B) in Scheme 2, both of which are possible intermediates in the biosynthesis of rhamnose from glucose. The branch carbon atom originates from C-3 or C-4 of glucose through a transannular rearrangement involving the carbonyl group in the intermediates (A) or (B). The presence of thymidine diphosphate rhamnose in S.griseus (Blumsom \& Baddiley, 1961), together with other thymidine diphosphate sugars (Baddiley, Blumsom, Di Girolamo \& Di Girolamo, 1961), suggests the possibility that the various rearrangements involved in the conversion of glucose into streptose take place with the sugars and intermediates attached to thymidine diphosphate.

Silverman \& Rieder (1960) have examined the distribution of radioactivity in $N$-methyl-L-glucosamine formed from the specifically labelled glucose. The isotope distribution was similar to that for streptose in our experiments (if it is assumed that C-5 of streptose is equivalent to C-6 of $N$-methyl-Lglucosamine), although rather more randomization of the ${ }^{14} \mathrm{C}$ had taken place during the formation of streptose. The increased randomization could have arisen in our experiments through the addition of $\left[{ }^{14} \mathrm{C}\right]$ glucose at zero time, whereas Silverman \&
Rieder (1960) added it after $60 \mathrm{hr}$. of growth. In a study of the formation of noviose by Streptomyces niveus (Birch, Holloway \& Rickards, 1962), $\left[1-{ }^{14} \mathrm{C}\right]$ glucose gave a product that contained $70 \%$ of the label in C-1 and [6-14 C]glucose gave a product with $80 \%$ of the label in C-6. (Our corresponding values for streptose were $67.5 \%$ and $76 \%$.) It seems, therefore, that the extent of randomization we have found is common in this type of experiment. Such randomization is usually accounted for by glycolysis (if redistribution of ${ }^{14} \mathrm{C}$ between $\mathrm{C}-1$ and C-6 is equal) or by the operation of the pentose phosphate-shunt pathway (if the randomization from C-1 is much greater than C-6). It seems that under the conditions we have used both of these pathways of glucose metabolism may have operated.

\section{SUMMARY}

1. The biosynthesis of streptomycin in Streptomyces griseus has been studied by adding to the growth medium possible precursors containing ${ }^{14} \mathrm{C}$ and degrading the streptomycin produced.

2. Procedures have been developed for the degradation of streptomycin to give information about the origin of individual carbon atoms in streptose and the methyl group in $N$-methyl-Lglucosamine.

3. The $N$-methyl group in the $N$-methyl-Lglucosamine residue of streptomycin arises from the $S$-methyl group in methionine and not from formate.

4. Experiments with glucose labelled at C-1 or C-6 confirm that the streptose residue arises from glucose, and support the previous suggestion that the $C$-formyl group in this branched-chain sugar arises from C-3 or C-4 of glucose. The $C$-formyl group does not arise from either formate or the $S$-methyl group in methionine.

We thank Glaxo Ltd. for a grant and for cultures of Streptomyces griseus. This work was also supported by grants from the Nuffield Foundation and the Department of Scientific and Industrial Research. 


\section{REFERENCES}

Baddiley, J., Blumsom, N. L., Di Girolamo, A. \& Di Girolamo, M. (1961). Biochim. biophys. Acta, 50, 391.

Birch, A. J., Cameron, D. W., Holloway, P. W. \& Rickards, R. W. (1960). Tetrahedron Lett. 25, 26.

Birch, A. J., Holloway, P. W. \& Rickards, R. W. (1962). Biochim. biophys. Acta, 57, 143.

Blumsom, N. L. \& Baddiley, J. (1961). Biochem. J. 81, 114.

Brink, N. G., Kuehl, F. A., Flynn, E. H. \& Folkers, K. (1946). J. Amer. chem. Soc. 68, 2557.

Carvajal, F. (1957). U.S. Pat. no. 2808364.

Corcoran, J. W. (1961). J. biol. Chem. 236, PC 27.

Galanina, L. A. \& Agatov, P. A. (1959). Dokl. Akad. Nauk S.S.S.R. $127,450$.

Hough, L. \& Jones, J. K. N. (1951). Nature, Lond., 167, 180.

Hunter, G. D., Herbert, M. \& Hockenhull, D. J. D. (1954). Biochem. J. 58, 249.

Hunter, G. D. \& Hockenhull, D. J. D. (1955). Biochem. J. 59, 268.

Hutchens, J. O. \& Kass, B. M. (1949). J. biol. Chem. 177, 571.

Karow, E. O., Peck, R. L., Rosenblum, C. \& Woodbury, D. T. (1952). J. Amer. chem. Soc. 74, 3056.

Kuehl, F. A., Flynn, E. H., Holly, F. W., Mozingo, R. \& Folkers, K. (1947). J. Amer. chem. Soc. 69, 3032.
Majer, J., Puza, M., Dolezilova, L. \& Vanek, Z. (1961). Chem. \& Ind. p. 669.

Majumdar, S. K. \& Kutzner, H. J. (1962). Appl. Microbiol. 10, 157.

Milton, R. F. \& Waters, W. A. (1955). Methods of Quantitative Micro-Analysis, p. 118. London: Edward Arnold and Co.

Morgan, K. J., Bardwell, J. \& Cullis, C. F. (1950). J. chem. Soc. p. 3190.

Peck, R. L., Graber, R. P., Walti, A., Peel, E. W., Hoffnine, C. E. \& Folkers, K. (1946). J. Amer. chem. Soc. 68, 29.

Peratoner, A. \& Tamburello, A. (1905). G. Sci. nat. econ. Palermo, 25, 272.

Phares, E. F. (1951). Arch. Biochem. Biophys. 33, 173.

Phares, E. F., Mosbach, E. H., Denison, F. W., Carson, S. F., Long, M. V. \& Gwin, B. A. (1952). Analyt. Chem. 24, 660 .

St John, C. V., Flick, D. E. \& Tepe, J. B. (1951). Analyt. Chem. 23, 1289.

Schenck, J. R. \& Spielman, M. A. (1945). J. Amer. chem. Soc. 67, 2276.

Silverman, M. \& Rieder, S. V. (1960). J. biol. Chem. 235, 1251.

Wood, H. G. \& Gest, H. (1957). In Methods in Enzymology, vol. 3, p. 287. Ed. by Colowick, S. P. \& Kaplan, N. O. New York: Academic Press Inc.

Biochem. J. (1964) 91, 35

\title{
Cellular Injury and Carcinogenesis
}

\section{ALKYLATION OF RIBONUCLEIC ACID OF RAT LIVER BY DIETHYLNITROSAMINE AND $n$-BUTYLMETHYLNITROSAMINE IN $V I V O$}

\author{
BY P. N. MAGEE* AND K. Y. LEE \\ Division of Oncology, The Chicago Medical School, Chicago 12, Ill., U.S.A.
}

\section{(Received 14 August 1963)}

Dimethylnitrosamine causes severe centrilobular haemorrhagic necrosis of the liver when administered to several laboratory animal species in doses near to the $\mathrm{LD}_{50}$ (Barnes \& Magee, 1954) and induces tumours of the liver, kidney and lung on repeated administration (Magee \& Barnes, 1956, 1962; Schmähl \& Preussmann, 1959; Zak, Holzner, Singer \& Popper, 1960; Argus \& HochLigeti, 1961). Diethylnitrosamine is less acutely toxic (Heath, 1962) but causes a similar acute liver necrosis in doses approaching the $\mathrm{LD}_{50}$. This compound induces liver tumours in the rat (Schmähl, Preussmann \& Hamperl, 1960; Argus \& HochLigeti, 1961 ; Thomas, 1961 ; Grundmann \& Sieburg, 1962) and tumours of the lung, nasal cavity and liver in the Syrian golden hamster (Dontenwill \& Mohr, 1961; Herrold \& Dunham, 1963). Very recently diethylnitrosamine has been shown to

* Present address: Toxicology Research Unit, Medical Research Council Laboratories, Carshalton, Surrey. induce malignant liver tumours in the guinea pig (Druckrey \& Steinhoff, 1962; Argus \& HochLigeti, 1963). This observation is of great interest since the guinea pig has been regarded hitherto as remarkably resistant to hepato-carcinogenesis.

$n$-Butylmethylnitrosamine is nearer in toxicity to dimethyl- than to diethyl-nitrosamine (Heath, 1961, 1962). It produces the typical acute hepatic injury in appropriate doses and is carcinogenic after repeated administration to the rat. In contrast tert.-butylmethylnitrosamine is considerably less toxic and does not cause necrosis of the liver (Heath, 1961, 1962). It does not appear to have been tested for carcinogenicity.

Druckrey and his colleagues have studied the relationship between chemical structure and carcinogenic activity in a series of nitrosamines and have found a large number of active compounds, several of which induce tumours of the oesophagus (Druckrey, Preussmann, Schmähl \& Müller, 1961). 